\title{
THE BIG SHAKE: DESIGNING TALL TIMBER BUILDINGS THAT ARE RESILIENT TO EARTHQUAKES
}

\author{
SIX UNIVERSITIES ARE INVOLVED IN A COLLABORATIVE \\ RESEARCH PROJECT TO INTRODUCE A SPECIAL TYPE OF \\ RESILIENT TIMBER BUILDING ACROSS THE UNITED STATES. \\ THE NHERI TALLWOOD PROJECT AIMS TO PROVE THAT TALL \\ TIMBER BUILDINGS CAN BE RESILIENT TO EARTHQUAKES, \\ WHILE HAVING A WHOLE HOST OF OTHER ADVANTAGES
}

\section{TALK LIKE A}

\section{STRUCTURAL ENGINEER}

Cross-laminated timber (CLT) - a type of wood panel created by gluing together layers of wood perpendicular to one another (similar to how plywood is manufactured).

Lateral loading - a horizontal force acting on a structure, such as wind, an earthquake or waves.

Mass timber - a category of framing techniques characterised by the use of solid wood panels and large-dimension wood columns and beams. CLT is a type of mass timber component.

Resilience - the ability of a structure to recover its functionality after experiencing the effects of an external disruptive force.

Rocking wall system - a type of structural design that allows walls in the building to move ('rock') when exposed to an external force and return to their original shape once the force has passed.

Seismic - an adjective used to describe effects related to earthquakes.

Shake table - a large platform that can reproduce earthquake ground shaking, used to test the seismic performance of buildings and other structures. The world's largest outdoor shake table used in this project is part of the NSF NHERI (Natural Hazards Engineering Research Infrastructure) programme, which provides this equipment to researchers when they need to test something really big.
Large-scale timber construction is on the up. New building techniques mean that many of the limitations of using wood are no longer insurmountable, and there is increased interest in timber as a sustainable building material. The production of steel and concrete accounts for $8 \%$ of all global CO2 emissions - a staggering amount - so finding alternatives for construction is essential. If harvested correctly, trees are a renewable resource and when they are incorporated into buildings, they also have an important role in keeping carbon out of the atmosphere.

Wood brings with it its own challenges. The danger of fire, for instance, requires careful attention, although the risks are much less than might be assumed and teams all over the world are helping to minimise these risks even further. Additionally, rigorous tests are used to investigate wood's structural capabilities, which are constantly improving as new engineering techniques are developed. Then, the buildings' responses to natural disasters, in particular earthquakes, must be considered. This is what the NHERI TallWood team focuses on.

The team consists of a mix of academics and practitioners, all keen on advocating novel construction methods. In particular, they want to demonstrate that their building techniques are resilient to earthquakes. Computer simulations and small-scale models are one thing, but the project aims to take it to the next level: to simulate an actual earthquake on a full-scale building. This involves a gigantic piece of equipment called a 'shake table', which does exactly what you might imagine.

\section{DR SHILING PEI}

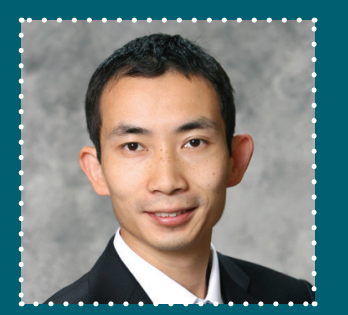

Shiling Pei P.E.

Associate Professor

Department of Civil and Environmental Engineering

Colorado School of Mines

Role: Project lead, overseeing the collaborative efforts between the six universities involved, and preparing for the 10 -storey shake table test.

Project: The NHERI TallWood Project aims to develop a resilience-based seismic design methodology for tall wood buildings of the future. This research project is supported by the National Science Foundation through a number of collaborative awards including: Civil, Mechanical and Manufacturing Innovation (CMMI) 1636164, 1634204, 1635363, 1635227, $1635156,1634628$. 


\section{DR JOHN VAN DE LINDT}

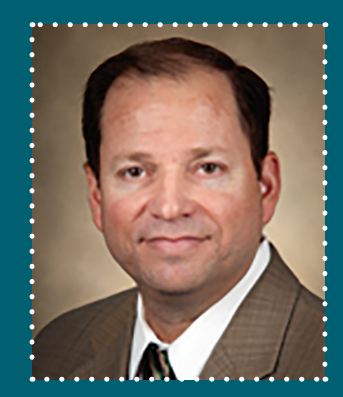

John W. van de Lindt

Harold H. Short Endowed Chair

Professor

Department of Civil and

Environmental Engineering

Colorado State University

Role: Leading the development of the project's design methodology and helping to plan the 10 -storey shake test for 2021.

\section{RESILIENCE AND PERFORMANCE}

Resilience is a vitally important part of structural engineering. It describes the ability of a structure to be able to 'bounce back' after it is impacted by a natural hazard such as an earthquake. Importantly, it is different from performance, which simply describes how well a structure can resist a force and keep damage to a minimum while protecting people inside. Resilience is often a better solution since performance only focuses on the building. Design codes based on performance minimally strive to preserve life safety, meaning people survive but the building may be unrepairable post-earthquake. The concept of resilience allows a building that becomes damaged to be more easily repaired and functional again, and support the recovery of the whole community around it.

BUILDING IN RESILIENCE

"There are two main ways that we can build resilience into a

structure," says John. "The first involves basic design, limiting the movement of the building to avoid damage to its components, or directing damage to sacrificial 'fuse' components that are easily replaceable. The second involves a complex computer model that simulates repair following damage." It is often impossible to avoid all damage in the event of an earthquake, but minimising it and even channelling it to less essential or easily repairable components can help make the repair process as easy as possible.

"We aim to go a step further than resilience of individual buildings," says John. "We want to build in community resilience, which means that society as a whole can remain functional after the earthquake, to support social institutions, the economy and overall societal wellbeing. Resilient buildings are an important component of community resilience - they are built with the community in mind. Especially following a natural disaster, buildings like these could become focal points to help an area's recovery.

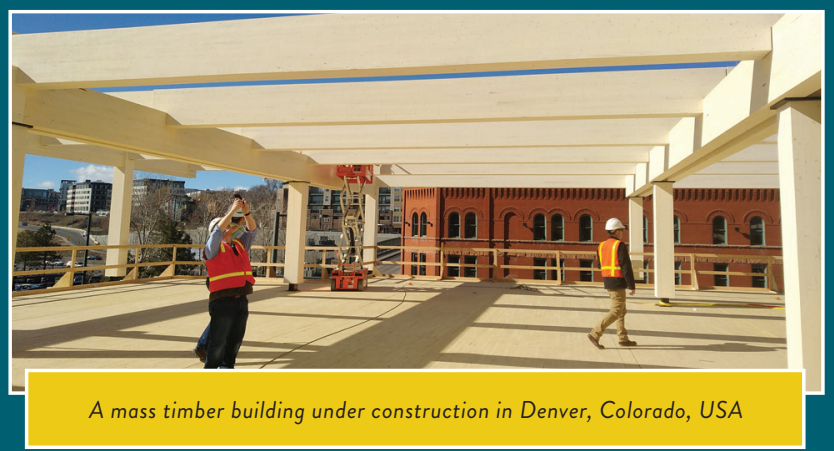

\section{DR JEFFREY BERMAN AND DR DANIEL DOLAN}

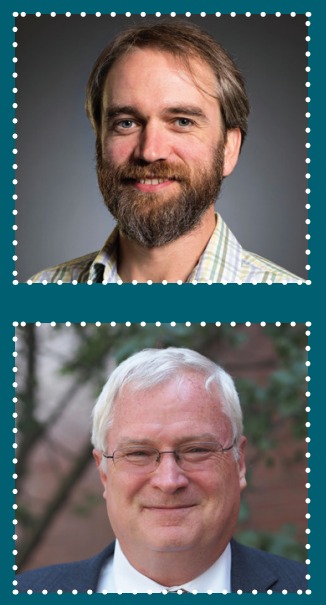

\section{Jeffrey Berman \\ Professor}

Department of Civil \&

Environmental Engineering

University of Washington

\section{J. Daniel Dolan, P.E. \\ Professor \\ Department of Civil and \\ Environmental Engineering \\ Washington State University}

Role: Building computer models to simulate the effects of an earthquake on the buildings the team is designing.

\section{VIRTUAL EARTHQUAKES}

Before getting underway with the shake table, it is important to have a good idea of what is going to happen. Building a ten-storey building and then giving it a good shake is no easy task, after all, so it is advantageous to be able to anticipate as many potential issues as possible, especially if there are ways the building design could be improved beforehand.
"We and our graduate students are responsible for predicting the seismic response of the ten-storey test using computer models," says Jeff. "These will help us understand how the design might be changed to improve the building's resilience." The team has particular goals in mind - for instance, limiting the damage from earthquakes of a particular intensity. Ideally, they want buildings to suffer no damage from smaller (and more frequent) earthquakes, and only repairable damage from larger (infrequent) earthquakes.

"Our simulations are founded in the science of mechanics," says Jeff. "Using advanced programming and applied math, the computer models replicate the physics of a building in an earthquake. This is actually quite complicated and involves a lot of learning to get it right."

\section{A SECOND ROCKING JOINT}

The team is investigating whether a second rocking joint could be beneficial. So far, the building rocks at ground level, before being pulled back into position. It is possible that putting a second joint halfway up (at the fifth storey) could further increase resilience. However, this brings its own challenges - for instance, ensuring the building and all its individual components have the capacity to be able to bend at this joint and fall back into place afterwards.

"So far, we have found that these CLT wall systems have excellent seismic performance," says Jeff. "They limit the damage to the structural components of buildings even in large and infrequent earthquakes." 


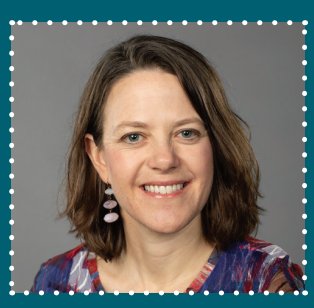

structural components are also crucial to a building's safety. Damage to stairs, for instance, can trap occupants within a building after a natural disaster, as happened in the 2011 Christchurch Earthquake in New Zealand.

\section{ALONG THE WALLS AND UP THE STAIRS}

The rocking wall system only works if everything moves with it. If the building's structure is designed to flex during an earthquake, the parts within its interior need to move with it or risk getting crushed or broken. This is known as deformation compatibility. "We are focusing on interior walls, the building envelope, and stairs as the most integral non-structural components," says Keri. "We are working closely with designers and other specialists to identify how to make improvements wherever we can."

For interior walls, they are investigating an innovative solution known as a 'slip track'. "This is when the top of the wall is not directly connected to the above floor slab, and thus can move independently or slip relative to the floor above." This works well until these walls meet at corners, at which point there is the risk of collision and damage. Now the team is working on the finer details of how to minimise damage at the corners.

Stairs are also a big area of interest. "Stairs are typically rigidly connected between floors and are often damaged during earthquakes, and are then deemed unsafe for future use," says Keri. "US building regulations have changed to address this, but there's still a lot of research that needs to be done to get the best design." Similar to interior walls, the prime solution is to detach the stairs from the floor at one end, so if the floors move independently the stairs are not stretched or compressed between the two. The team has partnered with a construction innovation company and will compare several solutions to solve this challenge.

Even if a building remains structurally sound after an earthquake, non-structural damage can ultimately harm its structural integrity. For instance, damage to exterior cladding (the building envelope) can mean that the underlying structure is exposed to weather. Many non-

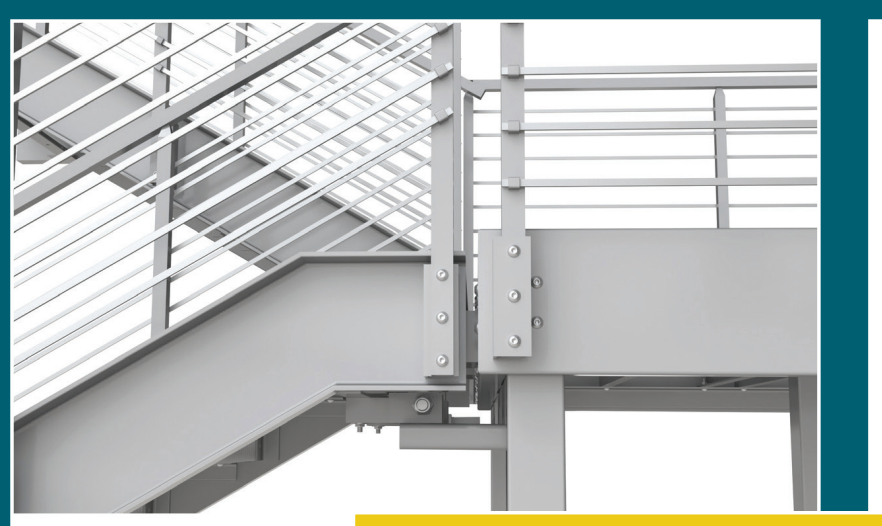

Left: Drift ready connection that accommodates relative movement between the stair flight and the landing. Right: Drift ready connection hardware. Courtesy of Construction Specialties, Ltd.
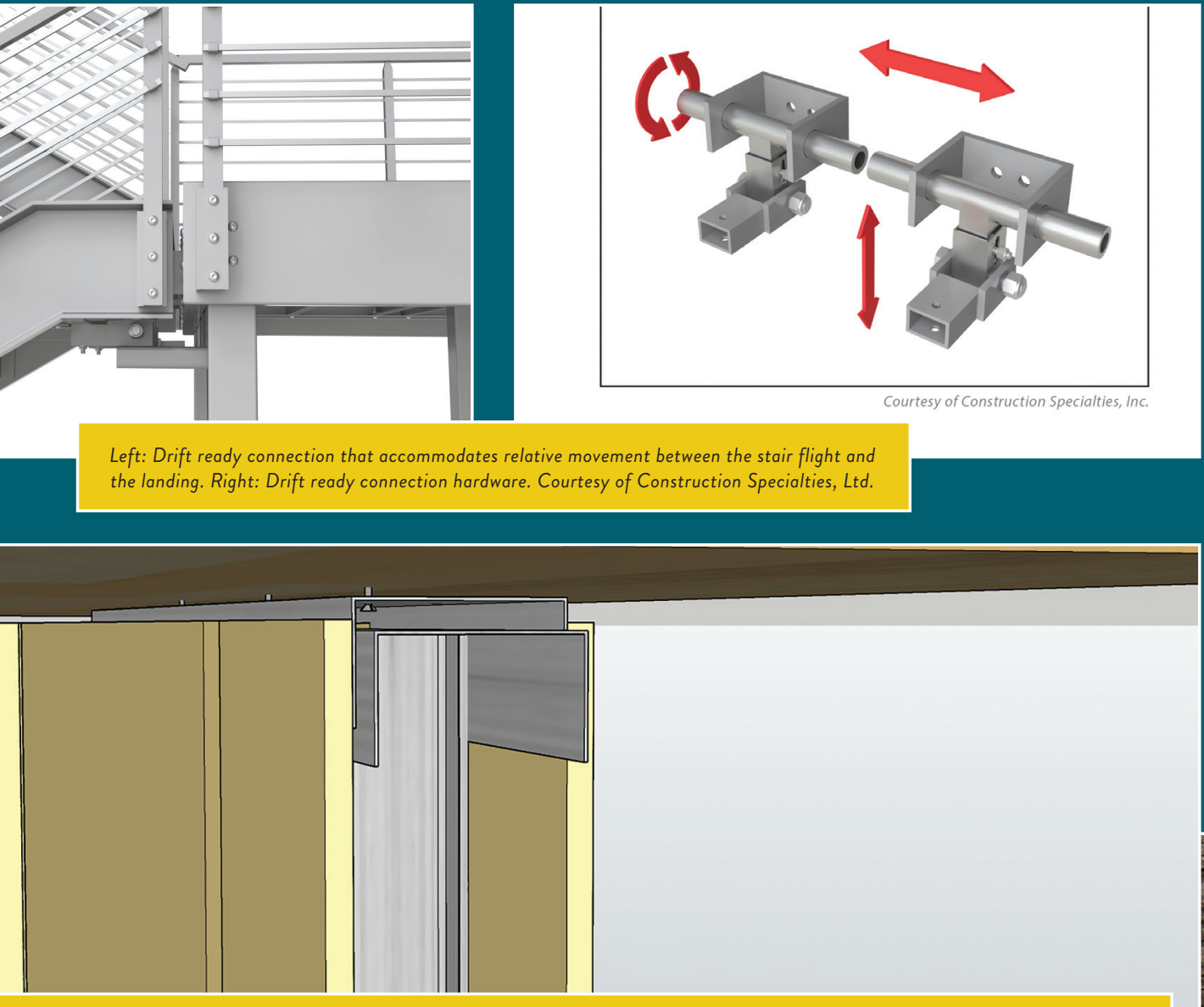


\section{DR JAMES RICLES AND DR RICHARD SAUSE}

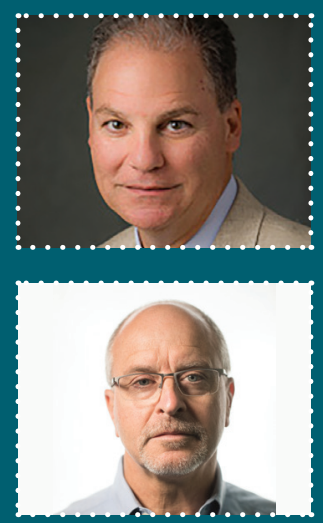

James M. Ricles

Bruce G. Johnston Professor of

Structural Engineering

Civil and Environmental Engineering

Lehigh University

\section{Richard Sause}

Joseph T. Stuart Professor of

Structural Engineering

Civil and Environmental Engineering

Lehigh University

Role: Investigating the effects of lateral force using subassemblies.

\section{FROM THE SIDE AND THE FRONT}

The Lehigh team investigates the lateral resistance of timber buildings with CLT walls. In particular, they examine bidirectional loading, which is when lateral force comes from several directions at once, as is common with earthquakes. For walls, this means examining what happens when forces parallel to the wall (for which it is designed) combine with forces perpendicular to the wall. The team is investigating this by building a constituent part of the building's walls and adjacent floors (a subassembly) and then using hydraulic actuators to subject the building to bidirectional forces.

"We developed specific software for these tests," says James. "The software uses real-time data, which gives it a highly realistic output." It also considers the interaction of walls with other components of the buildings, such as stairs and floors. This is important as any part of the building can influence its overall resilience, so making sure to account for everything is crucial. It is the first time that these walls have been tested in this way in the USA.

\section{RESULTS FOR THE REAL WORLD}

"Testing a large-scale building requires careful consideration of what we aim to find out," says James. "This is in addition to managing costs and schedule, as well as maintaining a safe environment for the research team." They must always make sure that their results reflect something of real-world value, something that usefully expands the knowledge available on this topic.

"We have found that the walls get damaged more easily when exposed to bidirectional loading rather than unidirectional loading," says James. "This has important implications for the building's seismic resilience, which will help us finalise the design details for the 10 -storey building."
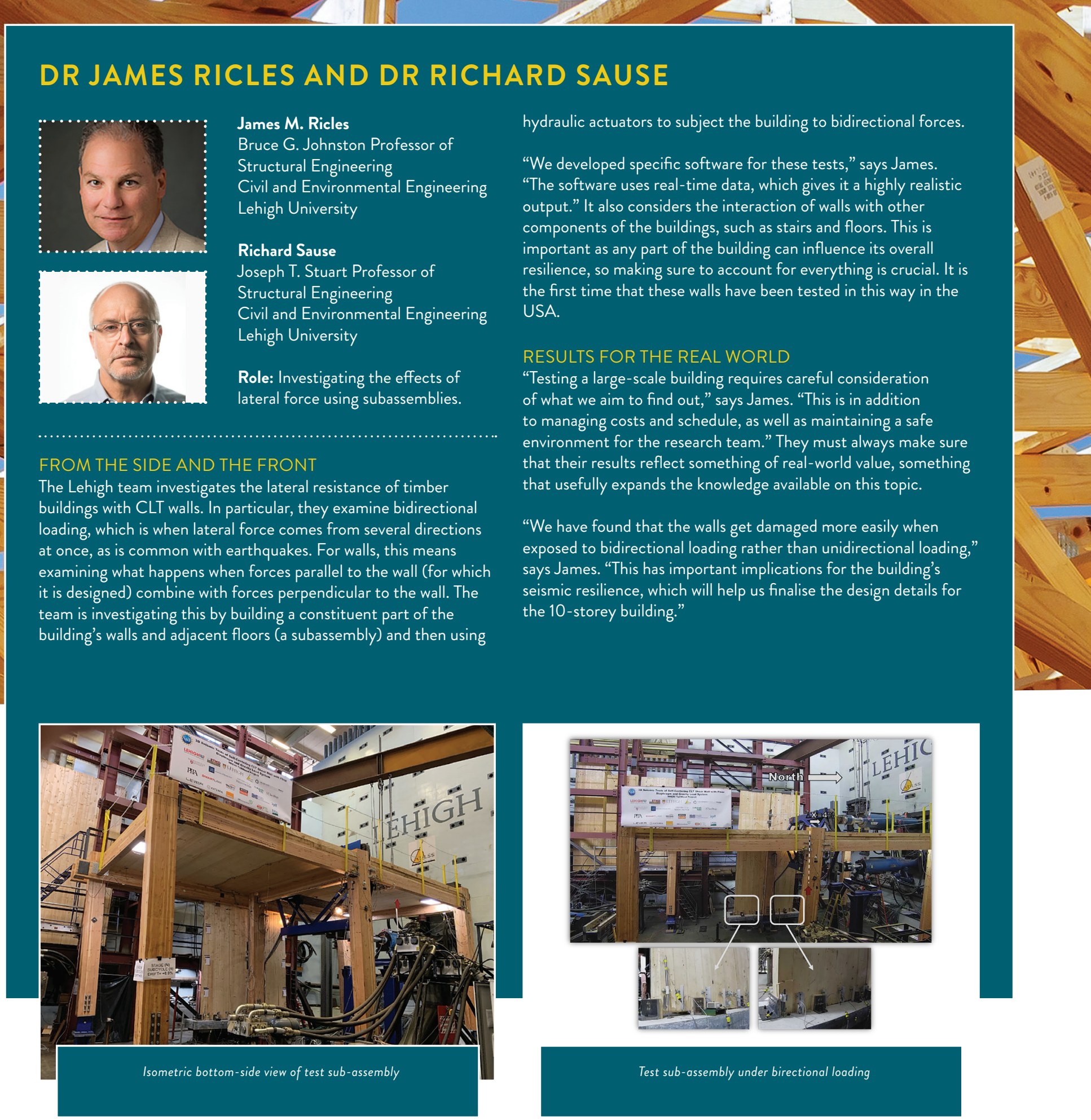

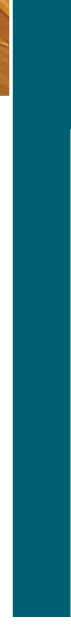

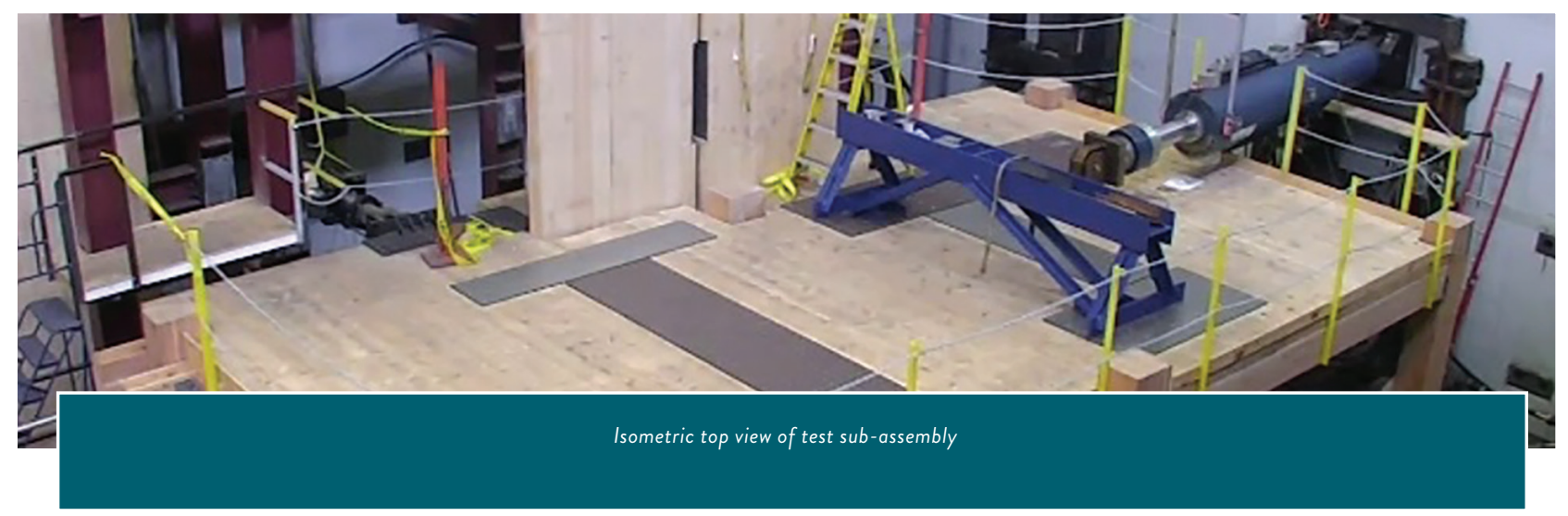




\section{CIVIL ENGINEERING AND}

\section{STRUCTURAL ENGINEERING: WHAT'S THE DIFFERENCE?}

Civil and structural engineering are two branches of engineering. In some ways they are closely related, but careers-wise they can follow quite different paths. In brief:

- Civil engineering is broader in scope and includes structural engineering as a specialty. General civil engineering tends to concern large-scale public systems, such as land development, transportation systems, water and energy distribution systems, and dams.

- Structural engineering concerns structures such as bridges and skyscrapers. It is focused on designing structures using steel, concrete, wood and masonry materials.

In terms of education, it is unusual to see a direct focus on structural engineering at the beginning of undergraduate study. Within civil engineering, students will often have the option to specialise in structural engineering at the end of the programme.

\section{GETTING INTO \\ CIVIL ENGINEERING}

- According to Top Universities, the best universities for civil engineering in the world are MIT, Delft University of Technology (Netherlands), Cambridge, University of California - Berkeley, and Imperial College London.

\section{- According to the Institute of Civil} Engineers, useful subjects to take to prepare for a civil engineering degree are maths, physics, geography and geology, computer science and languages.

- Civil engineering careers do not always require a degree. Apprenticeships are relatively common for this discipline both in the US and the UK. In the UK, the top employers for engineering apprenticeships are BAE Systems, National Grid and BAM Nuttall.

- Civil engineering is often a well-paid career. The average civil engineer in the US makes around $\$ 87,000$ a year, according to US News.

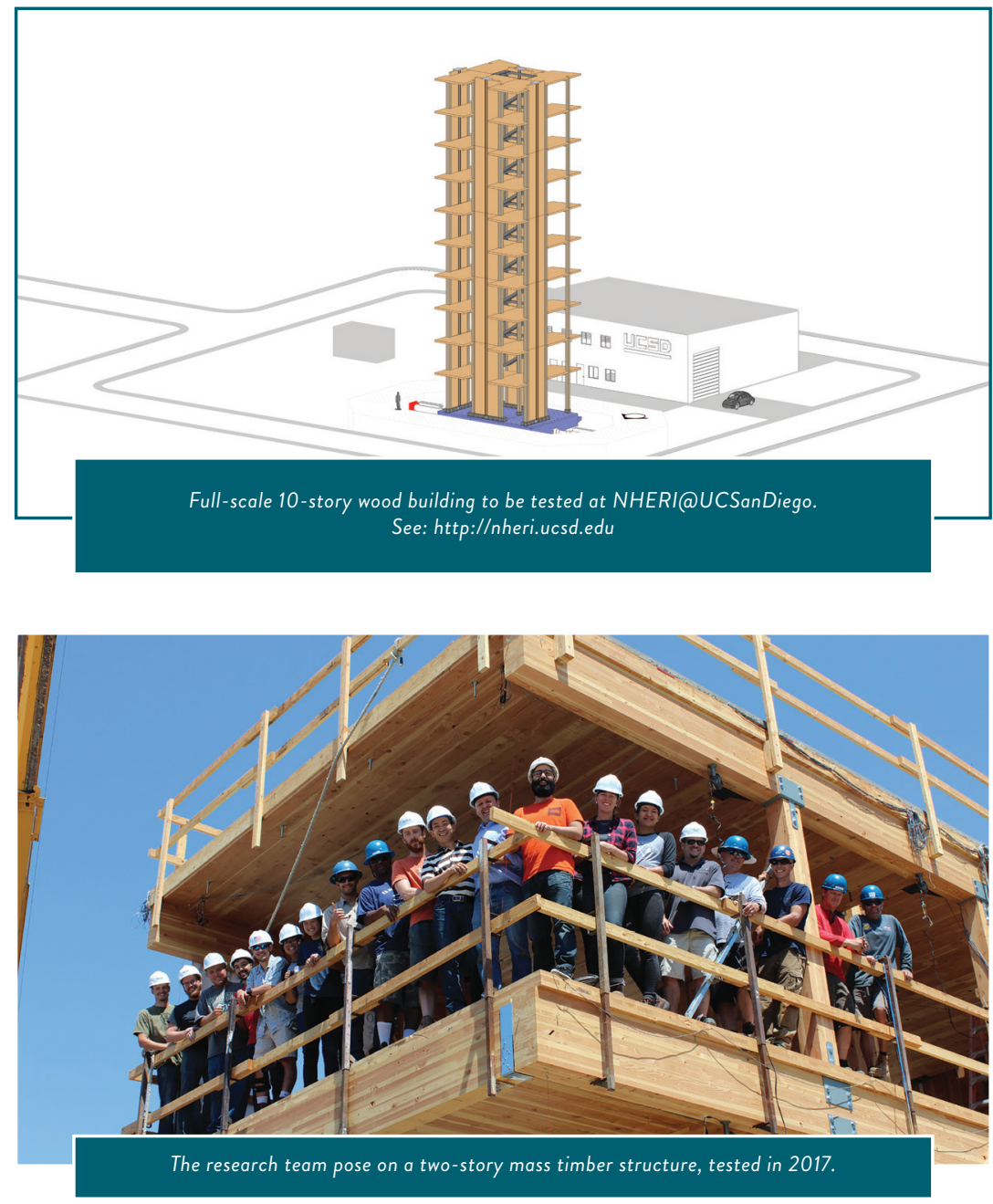

